\title{
Mechanical Characterization of Normal Strength Carbon Fibers Reinforced Concrete
}

\author{
Manish A. Kewalramani ${ }^{1}$
}

\begin{abstract}
Carbon fiber is a relatively new raw material which is confidently managing performance-cost trade off in construction sector. It is usually combined with other materials to form a composite. Owing to advantageous characteristics like high stiffness, high tensile strength, low weight, high chemical resistance, high temperature tolerance and low thermal expansion utilization of carbon fibers in construction sector is undeniably innovative. Besides, availability of various grades of carbon fibers with varying properties make it possible to be used for specific applications. The present work investigates the potential use of carbon fibers as reinforcement to normal strength concrete by studying important mechanical characteristics like compressive strength, splitting tensile strength, relationship between compressive strength and splitting tensile strength, and chord modulus of elasticity measured from stress-strain curves when high intensity long chain polymers primarily made of polypropylene are added to M40 grade concrete mix specimens in six different proportions and three different lengths. The non-destructive testing parameter-ultra sonic pulse velocity is determined for qualitative assessment of concrete specimens cast and is correlated with proportion and length of fibers added to concrete specimens. All obtained results are compared with non-fibrous concrete specimens. The results indicate carbon fibers as effective reinforcement material with increased ductility in normal strength concrete.
\end{abstract}

Keywords - Carbon Fibers, concrete, compressive strength, splitting tensile strength, ultra sonic pulse velocity.

\section{Introduction}

Reinforced Concrete (RC) is the most widely used construction material in the world. Several civil engineering structures use RC as its primary construction material. Concrete is strong in compression, but weak in tension or flexure, requires steel as common tensile reinforcement component in RC. Steel performance in RC is considered to be excellent, however steel tend to deteriorate over period of time. The present research work is intended to investigate alternative non-metallic reinforcement for concrete structures. Locally available Fibermesh-300, a synthetic carbon fiber has been used as micro-reinforcement system for concrete. Such a system is found to be accepted by National Building Codes as an alternate method of secondary reinforcing to traditional $\mathrm{RC}$, while the other advantages this synthetic fiber being rustproof, nonmagnetic, alkali proof, requires no minimum amount of concrete cover, safe and easy to use resulting in overall time saving. Moreover, micro-reinforcing with Fibermesh-300 is a purely mechanical process, which does not require any additional water or other mix design changes at normal rates. Fibermesh-300 fibers are compatible with all concrete admixtures and performance enhancing chemicals.

\footnotetext{
${ }^{1}$ Manish A. Kewalramani, Assistant Professor of Civil Engineering, College of Engineering, Abu Dhabi University.

United Arab Emirates (UAE)
}

Carbon fibers are usually confused with fiber glass as they both are similar in manufacturing resulting in some common products. But the basic difference between the two being-fiber glass is a polymer that is reinforced with silica glass strands, whereas carbon fiber is reinforced with carbon. They both have different chemical composition and properties, for e.g. carbon fiber is much stronger and stiffer, while fiberglass is more flexible. Carbon fiber is very rigid, being a very important characteristics from civil engineering perspective, as rigidity or stiffness of a material is a measure of deflection under stress [1]. Carbon fiber reinforced plastic is over four times stiffer than glass reinforced plastic.

Present work includes experimental investigation of normal strength M40 grade concrete specimens reinforced with Fibermesh-300 carbon fibers in various volumetric proportions and three available lengths of fibers. The parameters like weight of concrete specimen, ultra sonic pulse velocity (UPV), characteristic compressive strength (CCS), splitting tensile strength, and chord modulus of elasticity using stress-strain (or load deformation curves of concrete specimens) are determine experimentally and compared with non-fibrous specimens. A linear relationship between splitting tensile strength and CCS of specimens is compared with other studies [2, 3, 4]. The results of the study indicate concrete fiber to be a prospective microreinforcing agent in $\mathrm{RC}$.

\section{Experimental Work}

\section{A. Ingredients}

- Cement: Commercially available Ordinary Portland Cement of 43-grade used for present study conforms requirements of Indian Standard Specifications IS: $8112-1989$, with fineness value of $298 \mathrm{~m}^{2} / \mathrm{kg}$ and specific gravity of 3.15 .

- Fine Aggregate: One type of locally available fine aggregate confirming to grading zone III as per IS: 3831970 (Table 4, Clause 4.3) having specific gravity of 2.77 and surface moisture value of $78.6 \mathrm{gms}$ was used.

- Coarse Aggregate: Locally available crushed lime stone coarse aggregates with maximum aggregate size of 20 $\mathrm{mm}$ having specific gravity of 2.711 and water absorption of $0.228 \%$ were used for present study.

- Water: Potable tap water was used for the preparation of concrete specimens and for curing of specimens.

- Super plasticizer: A high performance super plasticizer named SV Superplast is a synthetic polymer based on melamine with specific gravity of $1.4-1.6$ and $\mathrm{pH}$ value of 8.5-9 was used.

- Carbon Fiber: Polypropylene fiber is a high intensity long chain polymer mainly made of polypropylene with density of order $0.91 \sim 0.93 \mathrm{~g} / \mathrm{cm}^{3}$ and tensile strength greater than $500 \mathrm{MPa}$ was used. The usual dosage recommended by supplier is $0.6-1.5 \mathrm{~kg} / \mathrm{m}^{3}$ of volume of 
total cementitious material. In present study, carbon fibers are randomly distributed in varied proportion of $0,0.6,0.8,1.0,1.2,1.4$, and $1.5 \mathrm{~kg} / \mathrm{m}^{3}$ with available length of $6 \pm 1 \mathrm{~mm}, 12 \pm 1 \mathrm{~mm}$ and $15 \pm 1 \mathrm{~mm}$ in concrete mix.

\section{B. Concrete Mix Proportion}

Concrete specimens cast using concrete mix of grade M40 with target compressive strength of $50.89 \mathrm{MPa}$ were used in present study. Mix proportion of ingredients used for cubic meter of concrete are shown in Table I. The average slump and compaction factor were observed to be $38 \mathrm{~mm}$ and 0.75 respectively.

TABLE I. MIX PROPORTION OF CONCRETE INGREDIENTS

\begin{tabular}{|c|c|}
\hline Ingredient & Quantity $\left(\mathbf{k g} / \mathbf{m}^{\mathbf{3}}\right)$ \\
\hline Cement & 581.31 \\
\hline Fine Aggregate & 373 \\
\hline Water & 177.3 \\
\hline Coarse Aggregate & 1291.82 \\
\hline Super plasticizer & $0.3 \%$ by weight of cement content \\
\hline
\end{tabular}

For mixing of ingredients, a tilting type mechanical mixer with a capacity of 85 liters was used. Initially, coarse and fine aggregates were mixed dry along with specific proportion of carbon fibers randomly added, and then super plasticizer was added to water and this suspension was mixed with coarse and fine aggregates as specified by the supplier. These ingredients were mixed till the mixture was thoroughly blended, followed by adding cement gradually at the end.

\section{Testing of Concrete Specimens}

Three cubes of M40 grade concrete were cast for each set of testing and average of results discussed is reported, for e.g. three specimens with $0.6 \mathrm{~kg} / \mathrm{m}^{3}$ of fiber content with length of $6 \pm 1 \mathrm{~mm}$ were cast. This way a total of 126 concrete cubes of size $150 \mathrm{~mm}$ were cast and tested in present study. The various parameters measured during testing procedure include weight of concrete cube, UPV, CCS determined on 28-day as per IS 516:1959, splitting tensile strength of cubes determined in accordance with IS 5816:1999 and chord modulus of elasticity measured from stress-strain curves. All the cubes were cured following standard sprinkling curing method for a period of 7-days.

\section{Results and Discussion}

\section{A. Characteristic Compressive Strength}

Fig. 1 depicts the variation of average CCS with different proportion of carbon fibers in three different lengths. In general, it can be observed that compressive strength of concrete increases with increase in length and content of carbon fiber. The increase in compressive strength is more predominant for $15 \pm 1 \mathrm{~mm}$ length fibers. On an average, a strength gain of almost $1.88 \%$ is observed with $0.6 \mathrm{~kg} / \mathrm{m}^{3}$ with increase in length of fibers from $6 \pm 1 \mathrm{~mm}$ to $12 \pm 1 \mathrm{~mm}$, and strength gain is approximately $2.79 \%$ when fiber length is increased to $15 \pm 1 \mathrm{~mm}$, compared to increase of $2.36 \%$ when no fibers are added to concrete mix. Hence, based on calculated strength gain with different length of fibers, an optimum range of fiber addition in general can be defined within $0.6 \mathrm{~kg} / \mathrm{m}^{3}$ to $1 \mathrm{~kg} / \mathrm{m}^{3}$ of concrete mix as the strength gain of order $0.64 \%$ and $1.74 \%$ respectively could be recorded with $1.5 \mathrm{~kg} / \mathrm{m}^{3}$ fiber content. The increase in average CCS may be related to uniform dispersion of carbon fibers throughout the specimens leading to consistent interior integrity, crack control and mode of failure by means of post-cracking ductility. However, higher length fibers in concrete mix cause crack closing forces leading to increase in compressive strength in addition to increased entrapped air which typically should reduce compressive strength. All such impacts in combination generally lead to little increase in compressive strength of normal strength concrete only when fibers added in some optimum proportion not resulting in increased entrapped air content.

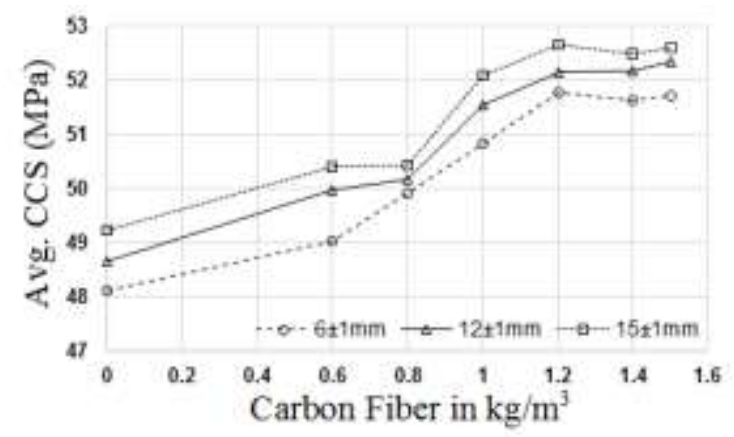

Figure 1. Characteristic Compressive Strength of M40 grade concrete with different length $(\mathrm{mm})$ and proportion $\left(\mathrm{kg} / \mathrm{m}^{3}\right)$ of carbon fibers

\section{B. Splitting Tensile Strength}

The results of splitting tensile strength indicate that all specimens in general exhibited a continuous increase in average splitting tensile strength with increase in proportion of carbon fibers. The increase was observed to be of the order $9.43 \%$ with $6 \pm 1 \mathrm{~mm}$ to $5.69 \%$ with $15 \pm 1 \mathrm{~mm}$ fibers in proportion $1.5 \mathrm{~kg} / \mathrm{m}^{3}$ compared to non-fibrous specimens as seen in Fig. 2.

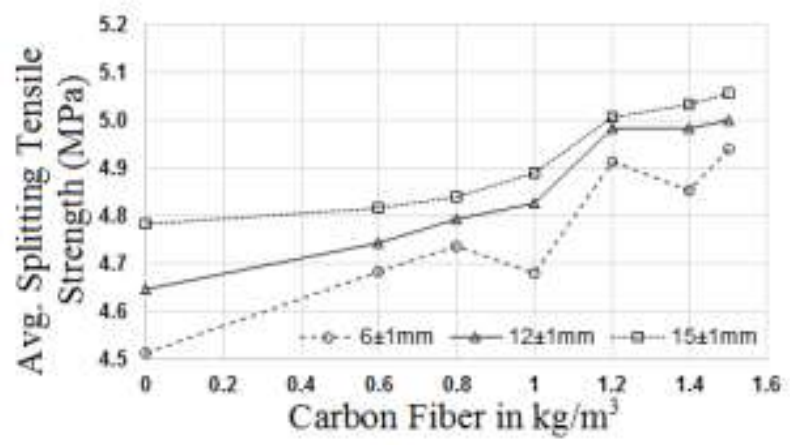

Figure 2. Splitting Tensile Strength of M40 grade concrete with different length $(\mathrm{mm})$ and proportion $\left(\mathrm{kg} / \mathrm{m}^{3}\right)$ of carbon fibers

Fig. 3 shows a linear relationship between splitting tensile strength and CCS experimentally calculated in present study. This figure also includes comparison with other work(s) relating splitting tensile strength with compressive strength of normal strength and high strength plain cement concrete. The results obtained in present study are in strong coherence with other studies [9]. Based on Fig. 
3 the relevant empirical expression obtained is given in (1) with coefficient of correlation $\left(\mathrm{R}^{2}\right)=0.711$.

$$
\sigma_{t}=0.1128 \sigma_{c}^{0.95}
$$

where $\sigma_{\mathrm{t}}=$ Characteristic compressive strength (28-day) in $\mathrm{MPa}$, and

$$
\sigma_{\mathrm{c}}=\text { Splitting tensile strength in MPa }
$$

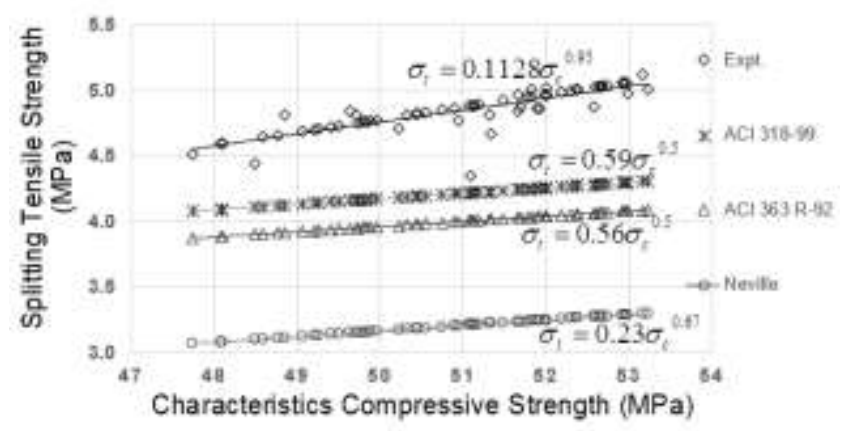

Figure 3. Relationship between splitting tensile strength and characteristic compressive strength comparison

\section{UPV measurements for qualitative assessment of concrete}

Non-destructive testing technique like UPV is often used for assessment of quality of concrete. The UPV procedure is robust and efficient if it is integrated with complementary compressive laboratory tests on concrete specimens [7]. Table II shows range of pulse velocity values for quality grading of concrete as proposed by IS 13311 (Part I): 1992, where a value below $3000 \mathrm{~m} / \mathrm{sec}$ indicates doubtful quality of concrete.

TABLE II. PULSE VELOCITY CRITERIA FOR QUALITY ASSESSMENT OF

\begin{tabular}{|r|c|c|}
\multicolumn{3}{|c|}{ CONCRETE } \\
\hline S. No. & Pulse Velocity $(\mathbf{m} / \mathbf{s e c})$ & Quality of Concrete \\
\hline 1. & Above 4000 & Excellent \\
\hline 2. & $3500-4000$ & Good \\
\hline 3. & $3000-3500$ & Medium \\
\hline
\end{tabular}

For present study, the pulse velocity of specimens lie in the range of 4862 to $5033 \mathrm{~m} / \mathrm{sec}$ indicating an excellent quality of concrete specimens cast with an average value of UPV as $4947.44 \mathrm{~m} / \mathrm{sec}$. Fig. 4 shows a relation between compressive strength and UPV of concrete specimens with varied length of fibers added. It can be clearly seen that UPV was affected by addition of fibers to concrete mix. Generally the addition of certain amount of fibers increase the UPV of mix as expected from specimens with higher proportion of carbon fibers than non -fibrous specimens. However, due to cumulative effect of superplasticizer, increase in amount of entrapped air voids and random orientation of fiber causing interruption to ultrasonic waves, UPV was observed to be more for concrete specimens with smaller length fibers or no fibers compared to concrete specimens with $15 \pm 1 \mathrm{~mm}$ fiber length.

\section{Chord Modulus of Elasticity}

Sound knowledge of compressive stress-strain response of concrete is needed for design and construction of concrete structures and evaluation of durability and service life of structure. Chord modulus of elasticity is one of the

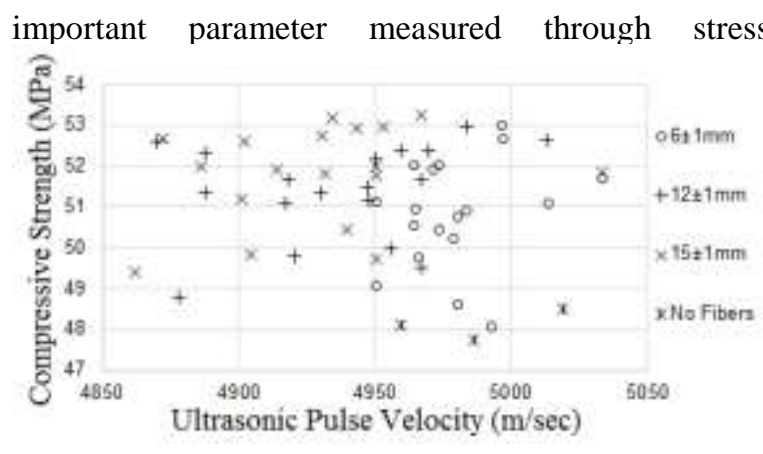

Figure 4. UPV of concrete specimen vs. compressive strength

response. It is given by the slope of a line drawn from a point representing a longitudinal strain of $0.00005 \mu$ $\mathrm{mm} / \mathrm{mm}$ (or 50 micro strains) to the point that corresponds to 40 percent of the ultimate load as recommended by ASTM C469 [8]. Shifting of base line by 50 micro strain is recommended as a correction for slight concavity that is often observed at the beginning of the stress-strain curve. Mathematically, chord modulus of elasticity is given by (2)

$$
E=\frac{\sigma_{2}-\sigma_{1}}{\varepsilon_{2}-\varepsilon_{1}}
$$

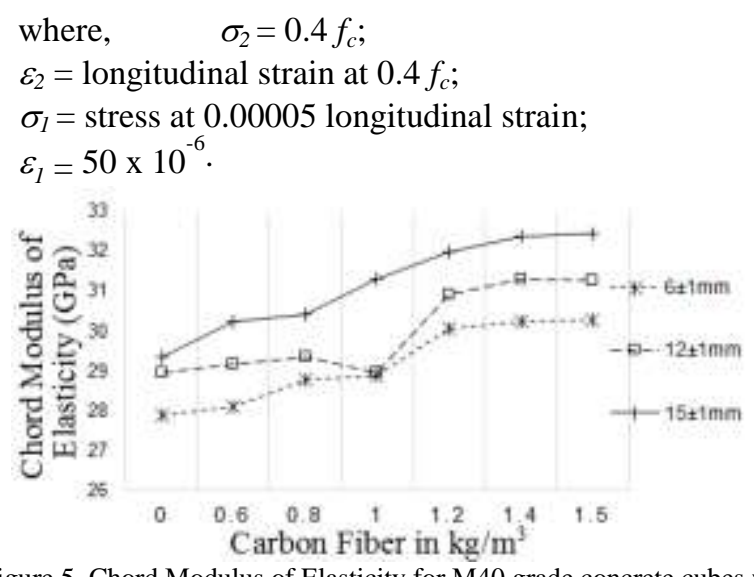

Figure 5. Chord Modulus of Elasticity for M40 grade concrete cubes with different proportion $\left(\mathrm{kg} / \mathrm{m}^{3}\right)$ and length $(\mathrm{mm})$ of carbon fibers

Fig. 5 shows variation in chord modulus of elasticity of M40 grade concrete cubes with different proportion $\left(\mathrm{kg} / \mathrm{m}^{3}\right)$ and length $(\mathrm{mm})$ of carbon fibers added to mix. A higher modulus of elasticity results from greater stiffness of mortar and its mortar-aggregate tensile bond strength, while on other hand lower modulus results from lower mortaraggregate tensile bond strength and a less homogenous composition of coarse aggregate causing the formation of more micro cracks at any strength level.

\section{Conclusion}

Addition of carbon fibers for achieving desired mechanical properties not only results in a dense and durable concrete mix, reduction in intrinsic cracks, no agglomeration and easy spread around in concrete mix, versatility to be used in any construction project but also it addresses environmental conservation concerns and cost effectiveness by reducing the amount of most energy intensive constituent (i.e. cement) in any concrete mix. The 
obtained results suggest that carbon fiber reinforcement is a better alternative to improve mechanical properties of concrete.

\section{References}

[1] Johnson, T., What is carbon fiber? - A beginner's guide to the lightweight composite material. Retrieved from URL http://composite.about.com/od/aboutcarbon/a/What-Is-CarbonFiber.htm

[2] A.M. Neville, Properties of Concrete, Fourth and Final Edition, United Kingdom, Pearson Prentice Hall, 1995.

[3] Building code requirements for structural concrete (ACI 318-99) and commentary (318R-99), American Concrete Institute, Farmington Hills, MI, 1999.

[4] State-of-the-Art Report on High Strength Concrete (ACI 363-R92), American Concrete Institute, Farmington Hills, MI, 2002.

[5] IS 383 (1970): Specification for Coarse and Fine Aggregates from natural sources for concrete.

[6] IS 516 (1959): Specification for Methods of Tests for Strength of Concrete

[7] Biondi, S., Valente, C., and Zuccarino, L., "Concrete Strength Evaluation through indirect UPV", Proc. Of Concrete Solutions, $5^{\text {th }}$ Int. Conf. on Concrete Repair, Northern Ireland, 2014.

[8] ASTM C 469: Standard Test Method for Static Modulus of Elasticity and. Poisson's Ratio of Concrete in Compression.

[9] Kinayekar, S. M., Gundakalle, V. D., and Kulkarni, K., The effect of addition of carbon fibers on mechanical properties of high strength concrete, Int. J. of Innovative Research in Science, Engineering and Tech., Vol.3, pp 8777-8784. 